\title{
GAMBARAN PENGETAHUAN PASIEN TUBERKULOSIS PARU DALAM PENCEGAHAN PENULARAN INFEKSI DI RUANGAN INTERNIS RUMAH SAKIT SANTA ELISABETH MEDAN
}

\author{
Jolly Wilthon Panjaitan ${ }^{1}$, Nagoklan Simbolon \\ Staf Pengajar dan Mahasiswa STIKes Santa Elisabeth Medan
}

\begin{abstract}
Background:Pulmonary Tuberculosis is an infectious disease that attacks the lung parenchyma, caused by mycobacterium tuberculosis. This disease can also spread to other body parts such as meninges, kidneys, bones and lymph nodes of pulmonary TB is a big problem for developing countries including Indonesia As most developing countries do. Almost all adult residents have been infected by $T B$ bacilli in easy times, since most pulmonary $T B$ disease in this country is caused by bacilli that undergo reactivity

Goals : To know the description of the patient's knowledge of TBC Lung prevention transmission of pulmonary tuberculosis infection in the internal room At Santa Elisabeth Hospital Medan.

Method: type of rancanagn case study used is descriptive number of subjects is as much as 9 Orang data collection in the form of questionnaires after that done scoring data is presented in the form of tables and distribution frequency

Results: From the case study the frequency distribution of respondents based on the use of the questionnaire. From the case study conducted (seen in table 4.1) that more male sex is 9 people $(100 \%)$ and female $0(0 \%)$. From this case study, the result is good..

Conclusion: Based on the results of the case studies described above, the authors conclude the case study results that the level of education greatly influences the patient's knowledge in preventing transmission of TB disease. It is evident that the level of education of the upperand upper-secondary patients with the highest proportion of case studies (55,5\%) know the mode of transmission of infection prevention.
\end{abstract}

Keywords: Tuberculosis, Prevention of Transmission of Infection

\section{PENDAHULUAN}

infeksi menular disebabkan oleh mycobacterium tuberculosis (Sylvia, 2005). Tuberkulosis yaitu penyakit infeksius, yang terutama menyerang parenkim paru (Smeltzer, 2001). TBC adalah penyakit menular yang disebabkan oleh mycobacterium tuberculosis, itu biasanya melibatkan paru-paru, tetapi juga terjadi pada ginjal, tulang, kelenjar adrenal, kelenjar getah bening, dan dapat disebarkan ke seluruh tubuh (Lewis, 2000)

Tuberkulosis dapat ditularkan dari satu orang ke orang lain melaui udara terutama batuk atau bersin. Hal ini akan menyebabkan terjadinya paparan partikel kecil yang dikenal dengan droplet nuclei yang melayang di udara dalam waktu cukup lama. Masing-masing droplet mengandung satu hingga 3 organisme. Diestimasikan bahwa sekitar $30 \%$ orang terinfeksi tuberkulosis apabila dalam waktu cukup lama terpapar/kontak dengan pasien tuberkulosis (Syamsudin, 2013). 
Menurut laporan WHO tahun 2011 penderita TB di dunia sekitar 12 juta atau 178 per 100.000 dan setiap tahunnya ditemukan 8,5 juta dengan kematian sekitar 1,1 juta. Kondisi ini lebih baik dibandingkan dengan tahun 2009 secara global dilaporkan sekitar $39 \%$ penyakit ini menyerang di asia terutama di 22 negara beban tinggi TB setiap tahunnya ditemukan kasus TB paru sekitar 9,4 juta dan kematian sebesar 3,8 juta. Dimana diperkirakan semua kasus TB yang ada di dunia sebanyak 14 juta lebih, pada umunya menyerang kelompok usia produktif. Berdasarkan data Rekam Medik Rumah Sakit Santa Elisabeth Medan pada tahun 2016 pasien yang dirawat inap dengan TB Paru berjumlah 223 pasien .

\section{METODE STUDI KASUS}

\section{Rancangan Studi Kasus}

Desain yang digunakan pada penelitian ini adalah deskriptif yang bertujuan untuk gambaran pengetahuan pasien tuberkulosis paru dalam pencegahan penularan infeksi di ruangan internis rumah sakit santa elisabeth medan tahun 2017

Peneltian deskriptif bertujuan untuk memaparkan peristiwa-peristiwa penting yang terjadi pada masa kini. Deskriptif peristiwa dilakukan secara sistematis dan lebih menekankan pada facta factual dari pada penyimpulan. Fenomena disajikan apa adanya dan manipulasi dan peneliti tidak mencoba menganalisis bagaimana dan mengapa fenomena tersebut bisa terjadi, oleh karena itu penelitian ini tidak memerlukan adanya hipotesis.

Jenis rancangan penelitian deskriptif pada penelitian ini adalah rancangan penelitian studi kasus. Studi kasus merupakan rancangan penelitian yang mencakup pengkajian satu unit penelitian secara intensif misalnya satu klien, keluarga, kelompok, komunitas atau institusi. Meskipun jumlah subjek cenderung sedikit namun jumlah variabel yang diteliti sangat luas hasil penelitian deskriptif sering digunakan atau dilanjutkan dengan melakukan penelitian analitik.

\section{Subjek Studi Kasus}

Penentuan kriteria sampel sangat membantu peneliti untuk mengurangi bias hasil penelitian studi kasus khususnya jika terhadap variabel-variabel kontrol ternyata pengaruh terhadap variabel yang kita teliti menurut (Nursalam, 2012).

Subjek studi kasus yang akan saya teliti adalah Gambaran Pengetahuan Pasien Tuberkulosis Paru dalam Pencegahan Penularan Infeksi di Ruangan Internis Rumah Sakit Santa Elisabeth Medan.

\section{Fokus Studi Kasus}

Fokus studi kasus adalah kajian utama dari masalah yang akan dijadikan titik acuan studi kasus. Fokus studi dalam penelitian studi kasus fokus yang akan dilaksanakan adalah Gambaran Pengetahuan Pasien dalam Pencegahan Penularan Infeksi.

\section{Definisi Operasional Studi Kasus \\ Defenisi operasional adalah mendefenisikan variabel secara} operasional berdasarkan karakteristik yang diamati. Memungkinkan peneliti untuk melakukan observasi atau pengukuran secara cermat terhadap suatu objek atau fenomena (Hidayat, 2010).

\section{Instrumen Studi Kasus}

Instrumen studi kasus merupakan sebuah alat untuk mengumpulkan data atau informasi yang bermanfaat untuk menjawab permasalahan studi kasus. Instrumen yang digunakan ialah berbentuk kuesioner. Kusioner ialah sejumlah pertanyaan tertulis yang digunakan untuk memperoleh informasi dari responden dalam arti laporan tentang pribadinya, atau hal-hal yang ia ketahui Dalam kusioner tersebut ada 10 pertanyaan setiap satu pertanyaan memiliki nilai. 


\section{Metode Studi Kasus}

Pengambilan Data

\section{Data primer}

Data primer adalah data tangan pertama atau yang diperoleh sendiri oleh peneliti dari hasil pengukuran, pengamatan dan survei (setady, 2007). Data dalam primer penelitian ini diperoleh secara langsung dengan memberikan lembar kuesioner kepada responden dan wawancara.

\section{Data sekunder}

Data sekunder adalah data yang diperoleh dari pihak lain, tidak langsung diperoleh peneliti dari subjek penelitiannya (Setiady, 2007). Hasil data sekunder penelitian ini diperoleh dari Rekam Medik Rumah Sakit Santa Elisabeth Medan.

\section{Penyajian Data Dan Nalisa Data}

Analisa data digunakan dalam penelitian ini adalah analisa univariat. Analisa univariat adalah untuk melihat hanya frekuensi pengetahuan pasien terhadap penularan penyakit Tbc.

Penyajian data yang digunakan dalam penelitian ini adalah tabel. Penyajian data dan tabel adalah pemaparan data hasil studi kasus dimasukkan kedalam tabel sehingga lebih jelas sifat data disajikan.

\section{Etika Penelitian}

Etika penelitian dilakukan peneliti dalam penelitian yaitu pertama peneliti memperkenalkan diri kemudian memberikan penjelasan kepada calon responden penelitian tentang tujuan penelitian dan prosedur pelaksanaan penelitian. Apabila calon responden bersedia maka responden dipersilahkan untuk menandatangani.

Peneliti juga menjelaskan bahwa responden yang diteliti bersifat sukarela dan jika calon responden tidak bersedia, maka calon responden berhak untuk menolak dan memunderkan diri selama proses pengumpulan data berlangsung. Penelitian ini tidak 25 menimbulkan resiko bagi individu. Yang menjadi responden, baik resiko fisik maupun individu. Yang menjadi responden, baik resiko fisik maupun psikologis (Nursalam, 2013).

\section{HASIL STUDI KASUS}

Berdasarkan data yang didapatkan dari Rumah Sakit Santa Elisabeth Medan, druangan (St. Pia, St. Lidwina, St. Martah, St. Pauline)

Dari hasil studi kasus yang dilakukan dapat dilihat pasien umumnya respondennya jenis kelamin laki-laki sebanyak 9 orang (100\%) sedangkan tingkat usia responden proporsi tertinggi adalah usia 40-44 tahun dan usia 45-49 tahun sebanyak 2 orang dan masingmasing (22,22\%), dan proporsi terendah adalah usia 50-54 tahun sebanyak 1 orang $(11,11 \%)$ sebanyak 1 orang $(11,11 \%)$, usia 30-34 tahun sebanyak 1 orang (11,11\%), usia 35-39 tahun sebanyak 1 orang (111,11\%), usia 40-44 tahun sebanyak 2 orang (22,22\%), usia 45-49 tahun sebanyak 2 orang $(22,22 \%)$, usia $50-54$ tahun sebanyak 1 orang $(11,11 \%)$, usia 55-59 tahun sebanyak 0 orang $(0 \%)$, usia 60-64 tahun sebanyak 1 orang $(11,11 \%)$. Dan usia 55-59 tahun 0 orang (0\%), usia 60-64 tahun sebanyak 1 orang $(11,11 \%)$.

Berdasarkan hasil jenis kelamin laki-laki sebanyak 9 orang $(100 \%)$ dan perempuan $0(0 \%)$, sedangkan tingkat usia 25-29 tahun sebanyak 1 orang 29 (11,11\%), usia 30-34 tahun sebanyak 1 orang (11,11\%), usia 35-39 tahun sebanyak 1 orang $(111,11 \%)$, usia $40-44$ tahun sebanyak 2 orang $(22,22 \%)$, usia 45-49 tahun sebanyak 2 orang $(22,22 \%)$, usia 50-54 tahun sebanyak 1 orang $(11,11 \%)$, usia 55-59 tahun sebanyak 0 orang (0\%), usia 60-64 tahun sebanyak 1 orang $(11,11 \%)$.

\section{Pembahasan}


Pengetahun pasien Tbc paru dalam hasil studi kasus menunjukan bahwa pengetahuan responden terhadap pencegahan penularan $\mathrm{Tbc}$ proporsi tertinggi adalah atau pencegahan penularan sebanyak 5 orang $(55,55 \%)$.

Hal ini sejalan dengan tingkat pendidikan responden mayoritas pendidikan SMA ke atas sehingga memiliki tingkat pengetahuan yang baik demikian juga pengetahuannya terhadap pencegahan penularan penyakit TBC paru.

\section{KESIMPULAN}

Berdasarkan hasil studi kasus yang telah diuraikan di atas dapatlah penulis menyimpulkan hasil studi kasus bahwa tingkat pendidikan sangat berpengaruhi terhadap pengetahuan pasien dalam pencegahan penularan penyakit $\mathrm{Tbc}$ hal ini terbukti bahwa tingkat pendidikan pasien mayoritas menengah ke atas (SMA dan sarjana) dengan proporsi tertinggi studi kasus $(55,5 \%)$ mengetahui cara penularan pencegahan infeksi.

\section{SARAN}

\begin{abstract}
Berdasarkan kesimpulan diatas dapatlah penulis memberikan saran supaya pasien yang menderita penyakit Tbc diberikan penyuluhan kesehatan tentang pencegahan penularan penyakit Tbc terutama pada pasien yang memiliki pendidikan rendah dalam (SMP ke bawah) hal ini penting karena pengetahuan seseorang di pengaruhi oleh tingkat pendidikan pengetahuan pasien terhadap pencegahan penularan Tbc paru atau berdampak terhadap insiden penyakit Tbc untuk itulah perawat sangat berperan dalam menurunkan insiden penyakit Tbc yang saat ini merupakan salah satu penyakit global.
\end{abstract}

\section{DAFTAR PUSTAKA}

Agus Riyanto Budiman, 2013. Kapita Selekta Kuesioner Pengetahuan dan sikap dalam Penelitian

Kesehatan. Jakarta. Salemba Medika.

Brunner Suddart, 2012 . Text book of Medical Nursing Vol. 1.

Irman Somantri, 2012 . Asuhan Keperawatan pada klien dengan gangguan sistem Pernafasan. Edisi 2. Jakarta. Salemba Medika.

Irman Sumantri, 2012 S.Kep., Ns., M.Kep. Asuhan Kperawatan Pada klien dengan Gangguan Sistem pernafasan Edisi 2.

Notoatmodjo, S. 2010. Metodologi Penelitian Kesehatan. Jakarta : Ribneka Citra.

Notoatmodjo, S. 2007. Promosi Kesehatan dan Ilmu Perilaku. Jakarta : Ribneka.

Notoatmodjo, S. (2005) Metode Penelitian Kesehatan. Edisi revisi. Jakarta. Rineke Cipta.

Notoatmodjo, S. 2003. Metodologi Penelitian Kesehatan. Jakarta : Ribneka.

Riyanto, Agus. 2011. Aplikasi Metodologi Penelitian Kesehatan. Yogyakarta : Nuha Medika.

Syamsudin Keban, Sesilia Andriani, 2013. Buku Ajar farmakoterapi gangguan Saluran pernafasan. Jakarta. Salemba Medika.

Sylvia A. Price, 2008 . Patofisiologi : Konsep Klinis Proses-proses Penyakit Kedokteran EGC. 